\title{
The Urban Informal Sector in an Adjusting Economy: The Case of Pakistan
}

\author{
MUHAMMAD ARIF SARGANA
}

\section{INTRODUCTION}

The concept of the informal sector has gained popularity since the well-known study by International Labour Organisation [ILO] in 1972 Kenya. Since then it has become a centre stage in policy discussion regarding unemployment and poverty alleviation. Though economists are still not able to give an authentic and unanimous definition of the informal sector, it is commonly known as the non-regulated sector of the economy. Despite the fact that the informal sector provides a large chunk of GDP and employment in the national economy, this sector is very much neglected in Pakistan. A few studies have been conducted to measure the size and the role of urban informal sector in past. However, the employment estimates provided by these studies have always been controversial. In addition, in all of these studies attention has been focused mainly to the manufacturing sector. Though the importance of the manufacturing sector cannot be denied, the services sector is also of significant importance as well, however it has received relatively less attention in the past. In this study, sufficient attention has been given to this neglected sector and focus is given to its role in employment in the urban informal sector.

As Pakistan is a signatory of the World Bank and IMF's stabilisation and structural adjustment programmes, which aim to reduce the budget deficit and restructuring of public sector employment, in the compliance with these programmes, retrenchment policies have been adopted in the government jobs by the respective governments. It is estimated that employment in the public sector has declined by about 10.6 per cent in period 1990 to 1992 only [Kemal.1995]. All of these measures have exacerbated the employment situation in Pakistan. In the light of above mentioned facts, it may be viewed that the urban informal sector has become more important in absorbing this surplus labour. Islamabad.

Muhammad Arif Sargana is Research Associate in ASIANICS Agro-Dev. International,

Author's Note: I am thankful to Prof. S. M. Naseem and Dr Howard White for valuable suggestions. 
Pakistan has experienced a rapid pace of economic growth in recent decades, but human capital is not matched that of physical capital. Despite much empirical evidence, tradition has held that that human capital is not much rewarded especially in the urban informal sector. Presently Pakistan spends less than 2.5 percent of its GNP [Pakistan (1996)] on education which is meagre in view of very low level of literacy. On other hand reliability of the figures about employment in informal sector by previous studies always remained questionable. In this paper earnings functions will be estimated including the human capital variables to see the affect of these variables on the earnings of the individuals.

Richard Sabot introduced the interaction term to capture the effects of schooling on experience. It explains that an educated person learns quickly as compared to an uneducated person. So schooling has a positive impact on experience. It might not be the case if the latter is doing the same job for generations or having more natural ability, in that case schooling would not have any impact on experience and the interaction term would be insignificant. In this study it has been included in earnings functions.

The structure of the study is as follows:

Part II consists of methodology and Part III discusses the data and its limitations. Part IV presents the regression analysis and statistical tests. Final part consists of concluding remarks and policy recommendations.

\section{METHODOLOGY}

Human capital theory has emerged in the economic literature with the seminal work done by Becker (1962) and Blaug (1969). Even before them in 1957 Jacob Mincer did the pioneer work on investment in human capital as part of his Ph.D dissertation entitled "A Study of Personal Income Distribution". However, he published it in 1972 separately under the title of "Schooling, Experience and Earnings" in which he presented the powerful theoretical model in which human capital is the central explanatory variable. In literature, it is also known as the "Earnings Function" and has been applied in this study to measure the wage differentials in the urban informal sector of Pakistan.

In case of Pakistan [Guisinger et al. (1984); Burki and Ubaidullah (1992) and Aftab and Rahim (1989)] have used the same model to estimate the rates of returns in the urban informal sector with small surveys. I have tested with my own survey data that has been conducted in the two cities of Pakistan Rawalpindi and Islamabad, with much focus to the service sector. The following most popular Mincerian model has been estimated:

$$
\ln Y i=B_{0}+B_{1} S c h+B_{2} E X P+B_{3} E X P^{2}+B_{4} D_{j}+U_{i}
$$


where

$\ln Y i=$ Wages/earnings of the ith individual.

Sch $=$ Years of schooling .

$E X P=$ Years of experiences (Age $-6-$ years of schooling).

$E X P^{2}=$ Square of Experience.

$D_{j}=$ Dummy variable for on the job training.

$U i=$ Random error term.

$B_{i^{\prime}}$ s are parameters to be estimated. In this specification, the coefficient of the variable measuring years of schooling can be interpreted as the private rate of return to schooling. It provides an estimate of the percentage increase in income due to one year's increase in schooling. $B_{3}$, the coefficient of experience square is expected having negative sign to prove the concavity of the experience-earnings profile. The dummy variable for on the job training assumes a value of zero for yes and one for no. Later, the interaction term has also been included in earnings functions.

Estimation has been segregated into subgroups of wage earners and selfemployed. Later on this informal sector has been divided into five small-scale activities namely, Petty Trading (PT), Domestic Servant (DS), Transport (T), Repair and Maintenance; Services (S) and Other Personal Services (OPS). Lastly equations are estimated separately for all of these sub-groups of the sector.

\section{DATA}

The analysis utilises primary survey data collected from the informal sector in the two cities of Pakistan. A small survey has been carried out in Rawalpindi and Islamabad for the study sponsored by ESCAP/UN to measure the poverty incidence in the urban informal sector of Pakistan. The total sample of 142 respondents was drawn on the principles of, stratified sampling. For the purpose Rawalpindi has been divided into 26 Mohallas and Wards and from Islamabad 4 markets have been covered.

A total of 111 (78 percent) respondents have been selected from Rawalpindi while 31 (22 percent) have been interviewed from the 4 markets of Islamabad. Special attention was given to choose the respondents who represent the informal sector i.e., those which belong to an enterprise small in size (standard criteria, workers must be less than 10). In the past most of the studies in the urban informal sector explore only the manufacturing sector but in this survey the neglected services sector has been more emphasised.

Out of total 142 respondents 45 belong to the Petty Trading category in our sample. Almost 94 percent of the respondents from this category are self-employed. Domestic servants got the minimum weight that is only 9.9 percent of the total sample. Services sector (Repair and Maintenance), which consists of some sort of semi skilled workers in the enterprises, represents about 22 percent in the total 
survey. The proportion of wage earners and self-employed is more evenly distributed, 33.1 percent of the total sample belong to the wage earners group and 66.9 percent represents the self-employed.

A short questionnaire was designed which consisted of 14 pages. It has been divided into five major modules:

1. Household module.

2. Occupation and location module.

3. Employment and income module.

4. Enterprise module.

5. Self Perception module.

- Impact of government policies.

- Public attitude.

- Co-operative assistance.

- Perceived solution.

Every module consists of on average 6 questions along with some supplement questions except the enterprise module that has some more detail and comprises of 16 questions.

In the second stage after the division of the areas into strata (Rawalpindi 26 Mohallas and Islamabad in 4 markets), intensity of the informal sector activities was mapped with some basic field checks and from the knowledge of previous studies. To make the survey representative of the entire city, it was decided that not more than 5 households should be selected from anyone of the strata (Mohallas) but within this number the selection varies with the intensity of the informal sector activities.

\section{Data Limitations}

Because of the small number of the women, a separate analysis for male and female is not possible. In Pakistan due to some social barriers and discrimination against women, they hardly enter into the labour force and it is also very difficult to cover more females in numbers in these small surveys.

Results of this survey directly are not comparable with previous studies, as they have been conducted in different years and in different cities. However, the direction and trend is comparable. On the basis of this survey estimates must be considered provisional and approximate for Pakistan as it hardly represents the whole country. However, it gives a good indication of the magnitude of human resources contribution in earnings in the urban informal services sector of Pakistan. 


\section{REGRESSION ESTIMATES}

\section{Earnings Functions for Wage Earners and Self-employed}

Table 1 presents the results for the whole sample and for both of the subgroups, wage earners and self-employed as well as with and without interaction term separately. Except all of this a dummy variable for on the job training has been also included in the estimation.

Table 1

Earnings Functions for Wage Earners and Self- employed (Log of Daily Earnings as Dependent Variable)

\begin{tabular}{|c|c|c|c|c|c|c|c|c|c|}
\hline & & hole Samp & & & Jage Earne & & & lf-employ & \\
\hline & (1) & (2) & (3) & (4) & (5) & (6) & (7) & (8) & (9) \\
\hline Int. & 4.101 & 3.89 & 3.77 & 4.06 & 3.74 & 3.36 & 4.030 & 3.88 & 3.93 \\
\hline Sch & $\begin{array}{c}0.034 \\
(1.44)^{* *}\end{array}$ & $\begin{array}{c}0.046 \\
(1.94)^{*}\end{array}$ & $\begin{array}{c}.057 \\
(5.50)^{*}\end{array}$ & $\begin{array}{l}-0.012 \\
(-.29)\end{array}$ & $\begin{array}{c}0.008 \\
(.19)\end{array}$ & $\begin{array}{c}0.059 \\
(3.06)^{*}\end{array}$ & $\begin{array}{c}0.045 \\
(1.56)^{* *}\end{array}$ & $\begin{array}{c}0.056 \\
(1.91)^{*}\end{array}$ & $\begin{array}{c}0.062 \\
(4.10)^{*}\end{array}$ \\
\hline EXP & $\begin{array}{c}.037 \\
(1.70)^{*}\end{array}$ & $\begin{array}{c}0.044 \\
(1.98)^{*}\end{array}$ & $\begin{array}{c}0.050 \\
(2.90)^{*}\end{array}$ & $\begin{array}{l}0.044 \\
(1.18)\end{array}$ & $\begin{array}{c}0.054 \\
(1.41)^{* *}\end{array}$ & $\begin{array}{c}.074 \\
(2.15)^{* *}\end{array}$ & $\begin{array}{c}.043 \\
(1.46)^{* *}\end{array}$ & $\begin{array}{c}.046 \\
(1.54)^{* *}\end{array}$ & $\begin{array}{c}0.043 \\
(1.90)^{*}\end{array}$ \\
\hline EXP2 & $\begin{array}{l}-0.0006 \\
(1.72)^{*}\end{array}$ & $\begin{array}{l}-0.0007 \\
(2.03)^{*}\end{array}$ & $\begin{array}{l}-0.0008 \\
(2.58)^{*}\end{array}$ & $\begin{array}{c}-0.0007 \\
(1.17)\end{array}$ & $\begin{array}{c}-0.0009 \\
(1.54)^{* *}\end{array}$ & $\begin{array}{c}-.001 \\
(2.00)^{* *}\end{array}$ & $\begin{array}{l}-0.0007 \\
(1.43)^{* *}\end{array}$ & $\begin{array}{l}-0.0008 \\
(1.47)^{* *}\end{array}$ & $\begin{array}{c}-0.0007 \\
(1.62)\end{array}$ \\
\hline Sch*EXP & $\begin{array}{l}0.0007 \\
(.824)\end{array}$ & $\begin{array}{l}0.0004 \\
(0.52)\end{array}$ & - & $\begin{array}{c}.002 \\
(1.22)\end{array}$ & $\begin{array}{c}.002 \\
(1.27)\end{array}$ & - & $\begin{array}{l}0.0002 \\
(2.15)^{*}\end{array}$ & $\begin{array}{l}-0.0002 \\
(2.15)\end{array}$ & - \\
\hline $\mathrm{Dj}$ & $\begin{array}{l}-0.198 \\
(2.76)^{*}\end{array}$ & - & - & $\begin{array}{l}-0.303 \\
(1.76)\end{array}$ & - & - & $\begin{array}{l}-0.169 \\
(2.07)^{*}\end{array}$ & - & - \\
\hline R2 & 0.24 & 0.21 & 0.45 & 0.29 & 0.23 & 0.21 & 0.22 & 0.18 & 0.18 \\
\hline RSS & 22.48 & 23.74 & 23.78 & 8.13 & 9.12 & 9.48 & 13.33 & 13.98 & 13.98 \\
\hline $\mathrm{N}$ & 142 & 142 & 142 & 47 & 47 & 47 & 95 & 95 & 95 \\
\hline
\end{tabular}

Results in the first equation of the Table 1 include, schooling, experience, experience square, interaction term and binary variable of on the job training. Results in Equation (1) show that all the human capital variables are significant. However, the interaction term has been proved insignificant. It suggests that Mincerian specification would have been approximately appropriate for the whole sample as well as for the sub-groups in the estimation.

The results show that income is an increasing function of education and experience. Differentiation of equation with respect to schooling gives the impact of additional year of schooling on the individuals earnings. It is shown that the impact of an additional year of schooling and experience on earnings is 3.4 and 3.7 percent respectively Equation (1). Equations (2) and (3) represent the results by excluding 
the interaction term and dummy variable of on the job training. After the exclusion of these variables the contribution of schooling in individuals earnings has been increased from 3.4 percent to 5.7 percent while the incremental contribution by experience has increased slightly from 3.7 percent to 5 percent only. It implies that the variables Sch*Exp and Dj affect negatively to schooling.

In second phase, wage equations are estimated separately for the subgroups of wage earners and self-employed. There are significant differences in the parameter estimates between the self-employed and wage earners. In self-employed all three regressions, the effects of schooling on earnings is highly significant. However, in the case of wage earners the coefficient of schooling becomes highly significant only after removing the interaction term and $\mathrm{Dj}$. For self-employed the estimated coefficient implies a 6.2 percent increase in wage rate for each additional year of schooling Equation (9). By applying the Mincer's earnings functions results indicate that rates of return to schooling for the urban informal sector individuals who are self employed is substantially higher, about 10.7 percent higher than the wage earners [Equations (6) and (9)]. The estimates for experience in the self-employed are lower than the wage earners as it is evident from the Equations (6) and (9). That one-year increase in experience would tend to increase the wage by about 7.4 percent for the wage earners while the comparable figure for the self-employed is only 4.3 percent. In all of the equations, the negative co-efficient of experience square (EXP2) shows that workers face a concave experience-earnings profile. Our results are in corroboration with Burki and Abbas (1991), Guisinger and Irfan (1980) and Khan (1983).

Dummy variable specification for different levels of education is presented in Appendix 2. ${ }^{1}$ By looking the results of equations with different level of education in Appendix 2, it becomes clear that returns to education for all levels are higher for self-employed. Interestingly earnings in the wage earners group have negative relation with incremental educational level. For the whole sample earnings tend to increase as the level of educational attainment increases. Among the educational categories considered, a sharp variation was observed among wage earners and selfemployed. By using the binary variables for different level of education, results corroborate our previous inference from the estimation presented in Table 1 that schooling has greater impact on self-employed earnings as compare to the wage earners while experience shows somewhat better contribution in the earnings of the wage earners. In the wage earners group, middle standard level of education has the lowest reward while highest goes to the individuals who have higher level of education. In contrast for self-employed highest reward would tend to go for individuals who attained the matriculation level of education. The coefficient of the work experience for both wage earners and self-employed are statistically significant at 5 percent level. Dummy variable for on the job training is significant and has expected sign in all the three equations. It can be interpreted that individuals who

${ }^{1}$ Appendix Tables are available with the author and can be had on request. 
does not have on the job-training earn 33.7 percent less than the individuals who attain on the job-training in the wage earners group while the comparable figure for the self-employed stands 17 percent.

In sum general conclusion can be drawn that education in the urban informal sector (both for wage earners and self employed) is an important and strong source of variation in earnings and investment in education exhibits decent returns across the sectors. At a gross level, the positive relationship of schooling and earnings support the hypothesis that education is an investment that receives pecuniary returns in labour market.

\section{Earnings Differentials in Small-scale Economic Activities}

Results in Table 2 show the pattern of returns to human capital variables of the five small scale economic activities, Petty trading (PT), Domestic servants (DS), Transport (T), Services [repair and maintenance] (S) and Other personal services (OPS) of the urban informal sector in Pakistan. Regression results show that all the coefficients of human capital variables have the anticipated sign and are statistically significant at the 5 percent level except the DS who are so small in sample, only 10 percent. It is evident in the table that private rate of return to schooling [Equation (3), (9), (12), and (13)] for PT is 3.4 percent, for Transport it is 2.5 percent, Services 4.4 percent and for OPS it is 17.5 percent. It can be concluded that schooling is highest rewarded in OPS and lowest in for the Transport workers. The coefficient of on the job-training is statistically significant only in petty trading it explains that PT workers who do not have on the job-training earn 30.2 percent less than the individuals who attained on the job-training. $\mathrm{R}^{2}$ is very respectable across the categories.

The coefficient of Experience Square (EXP2) in PT is positive which shows that people don't stop to work even in the old age. On the other hand highest reward for experience are shown in $\mathrm{T}$ sector, which are 15 percent with an additional year of experience. Results in Table 3 indicate that highest rewards are going to the individuals who have middle level of education and employed by the OPS sector these are 60.1 percent. Only in the transport sector D2 is significant and it shows 43.4 percent higher rewards as compare to the reference group which is uneducated or having less than 3 years of schooling. In general it can be concluded that human capital variables are contributing in the earnings among all of these categories. On the job training is only important for petty traders while the experience is highest paying in transport sector. Except the PT, among all the categories Experience square (EXP2) proves the concavity.

\section{Normality Test}

Modern statistical techniques stress more on the role of data in model specification. Implicitly in earnings functions, it is assumed that the data is normally 
Table 2 
Urban Informal Sector in an Adjusting Economy

Table 3

Earnings Functions for Small-scale Activities

(Log of Daily Earnings as Dep. Variable)

\begin{tabular}{lccccc}
\hline & PT & DS & T & S & OPS \\
& $(1)$ & $(2)$ & $(3)$ & $(4)$ & $(5)$ \\
\hline Intercept & 5.14 & 4.02 & 3.09 & 3.67 & 2.86 \\
D2 & 0.086 & 0.103 & 0.434 & .0356 & 0.138 \\
& $(0.52)$ & $(0.35)$ & $(1.56)^{*}$ & $(1.12)$ & $(0.61)$ \\
D3 & 0.326 & - & 0.196 & 0.122 & 0.601 \\
& $(1.93)^{*}$ & & $(1.25)$ & $(0.53)$ & $(2.97)^{*}$ \\
D4 & 0.324 & - & 0.172 & 0.464 & 0.564 \\
& $(1.65)^{* *}$ & & $(0.80)$ & $(2.44)^{*}$ & $(2.12)^{*}$ \\
D5 & 0.323 & - & 0.201 & 0.172 & 1.32 \\
& $(1.22)$ & & $(0.57)$ & $(0.45)$ & $(4.25)^{*}$ \\
EXP & -0.036 & -0.019 & 0.155 & 0.085 & 0.112 \\
& $(0.88)$ & $(0.32)$ & $(2.37)^{*}$ & $(2.26)^{*}$ & $(2.68)^{*}$ \\
EXP2 & 0.0007 & 0.0006 & -0.003 & -0.002 & -.002 \\
& $(0.85)$ & $(0.66)$ & $(2.33)^{*}$ & $(2.29)^{*}$ & $(2.15)^{*}$ \\
Dj & -0.324 & -0.05 & 0.037 & -.014 & -0.061 \\
& $(2.46)^{*}$ & $(0.15)$ & $(0.21)$ & $(0.08)^{*}$ & $(0.38)$ \\
R2 & 0.32 & 0.38 & .54 & 0.42 & 0.52 \\
RSS & 5.16 & 1.60 & 0.66 & 3.33 & 3.56 \\
$\mathrm{~N}$ & 45 & 14 & 19 & 31 & 33 \\
\hline
\end{tabular}

-Values in parenthesis are $t$-statistics.

* Significant at the 5 percent level.

**Significant at 10 percent level .

distributed. If it is not so, it is important to make it normally distributed otherwise it can create a problem in estimation and hypothesis testing. It is observed presence of any outlier or skewness in any of the variable could mislead the inference made by that estimation. More often in this univariate analysis-data distribution-mean based and order based techniques are used. Mean of the variable is important to look into the distribution of variable. However, this measure tells us little about the data. To cope with this problem generally it is useful to look into the shape of the empirical distribution, which shows the pattern of variable of the data. ${ }^{2}$

${ }^{2}$ For detail see Mukerjee et al. (1998), pp. 78-91. 
Fig. 1.

Fig. 2.

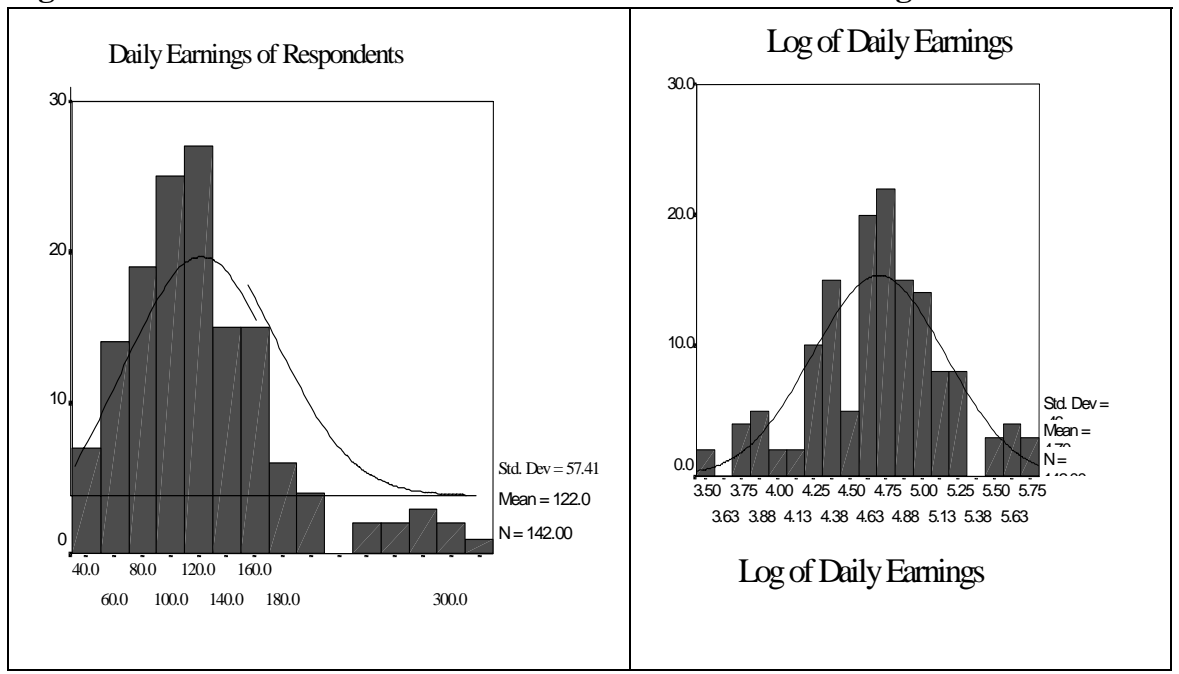

To detect any normality in the data both quick exploratory check and formal test have been applied in this paper. Figure 1 and 2 presents histograms for the distribution of the variable earnings using the semi logarithmic and linear specification. In these figures logarithmic distribution conforms much more closely to the normal distribution than for the linear distribution. That confirms the correct model specification. Another method to detect the skewness in the data, is to compare the sample mean with that of the sample median. It is evident in Appendix 1 that mean daily earnings Rs 121.9 is greater than the sample median Rs 114.3. That indicates the positive skewness which has been removed from the data by taking the logarithmic for of the variable daily earnings. After taking the log of daily earnings mean and median come very close to each other. All other variables show that sample has been drawn from a normal distribution. ${ }^{3}$ Box plots of the variable have not shown any outlier.

\section{HETROSKEDASTICITY}

In the cross section data, Hetroskedasticity is the most common problem. Presence of the Hetroskedasticity inflates the $t$-values that can mislead to make any inference from estimated coefficients. So, in the basic specification of the model it is assumed that the disturbance term is homoscedastic with respect to schooling and experience. Hetroskedasticity can be easily detected from the plot of absolute residuals against the predicted values of regression. ${ }^{4}$ Glejser's test is another important measure to find the Hetroskedasticity in the data Figure 3.

${ }^{3}$ For detail see Appendix 5.

${ }^{4}$ If the plot of absolute residuals shows spread of points vertically wider and wider with the increase in the predicted values or vise versa, it is the indicator of the presence of Hetroskedasticity. For detail see Mukerjee et al. (1998), pp. 254. 


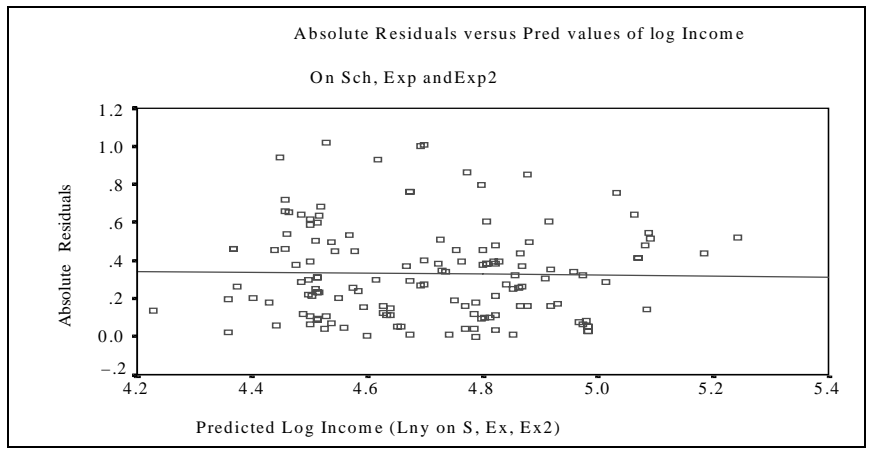

Fig. 3.

Both of the measures have been utilised in this paper to detect hetroskedasticity in the model. Glejser's test that involves regressing absolute residuals separately on the explanatory variables, on their inverse and square roots. Then t-test is used to test whether the slope coefficients are significantly different from zero. ${ }^{5}$ The $t$-tests for the slope coefficients equal to zero are significant. Hence the hypothesis of the homosedasticity is rejected.

\section{IV.V. General Test of Independence}

The situation where the data is qualitative instead of quantitative, it is not possible to measure the degree of association by means of the correlation coefficients. A general test of association is purposed by Thomas (1983) to measure the association between two variables.

Since data presented in Table 4 is not suitable for co-relation analysis. If we

Table 4

Actual Frequency Table

\begin{tabular}{lcccccc}
\hline Income Level & $\begin{array}{c}\text { Below } \\
\text { Primary }\end{array}$ & Primary & Middle & Matric & Higher & Total \\
\hline$\leq 3000$ & 43 & 13 & 11 & 9 & 6 & 82 \\
$3000>8000$ & 13 & 8 & 19 & 16 & 4 & 60 \\
& 56 & 21 & 30 & 25 & 10 & 142 \\
\hline
\end{tabular}

Source: Author's Calculations.

$$
\begin{aligned}
&{ }^{5} \mathrm{LnYi}=4.486+ 0.0004 \mathrm{Sch} \\
&(4.90) \\
& \mathrm{LnYi}=4.69+ 0.031 / \mathrm{Sch} \\
&(0.12) \\
& \mathrm{LnYi}=4.46+0.130 \sqrt{\mathrm{Sch}}
\end{aligned}
$$


assume that education and earnings are independent, expected frequency table can be constructed by calculating the probability of a person, expected in the range of less than Rs 3000 earnings per month and having less than 3 years of schooling and so on. In a random selection, the probability of person expected in this range would be $56 / 142=0.394$. If we assume that educational attainment and earnings are mutually exclusive, we would expect those total persons in the range of less than Rs 3000 earnings and having less than 3 years of schooling would be $82 X(0.394)=32$. Similarly all the other values can be filled in the same way, presented in Table 5.

Table 5

Expected Frequencies Table

\begin{tabular}{lcccccc}
\hline Income level & $\begin{array}{c}\text { Below } \\
\text { Primary }\end{array}$ & Primary & Middle & Matric & Higher & Total \\
\hline$\leq 3000$ & 32 & 12 & 17 & 14 & 7 & 82 \\
$3000>8000$ & 24 & 9 & 13 & 11 & 3 & 60 \\
& 56 & 21 & 30 & 25 & 10 & 142 \\
\hline
\end{tabular}

Source: Author's Calculations

Degree of freedom has been calculated by $(\mathrm{r}-1)(\mathrm{c}-1)$ where $\mathrm{r}$ stands for rows and $\mathrm{c}$ for columns, that is 4 . In the following $\chi^{2}$ value has been calculated:

$$
\begin{aligned}
\chi^{2} & \left.=(43-32)^{2} / 3+(13-24)^{2} / 24+13-12\right)^{2} / 12+(8-9)^{2} / 9 \\
& +(11-17)^{2} / 17+(19-13)^{2} / 13+(9-14)^{2} / 14+(16-11)^{2} / 11 \\
& +(6-7)^{2} / 7+(4-3)^{2} / 3=18.43
\end{aligned}
$$

At 95 percent probability level with 4 degree of freedom the critical value is 9.48. Since our calculated value of $\chi^{2}$ is 18.43 which is greater than 9.48, we reject the hypothesis that there is no association between education and earnings in the urban informal sector of Pakistan.

\section{Robustness Test}

To make the sense of regression coefficients, robustness is presented in graphical as well as by statistically method. ${ }^{6} \mathrm{~A}$ visual representation is given in Figure 4 and 5 which shows the box plots of the absolute $t$-statistics and normalised coefficient. Each coefficient is normalised by the average of the absolute values of the coefficients for that variables across all estimated equations. Results of all the 63 regression estimates are presented in Appendix 1. Comparative box plots have been shown in Figure 4 and 5. Figure 4 represents box plot of the absolute $t$-statistics and Figure 5 shows the box plots of the normalised coefficients. Box plots of the absolute

${ }^{6}$ See Mukherjee et al. (1998), pp.198-204. 
$t$-statistics shows that estimates of the variable on the job training and schooling are the most stable variables among all its counterparts. In contrast, the coefficient of dummy variable for region (Rawalpindi/Islamabad) proves highly insignificant in all the specifications. This is in corroboration of the Chow test result presented in the previous section. In general , it can be said that the coefficients of the human capital variables are stable, with partial exception Figure 5.
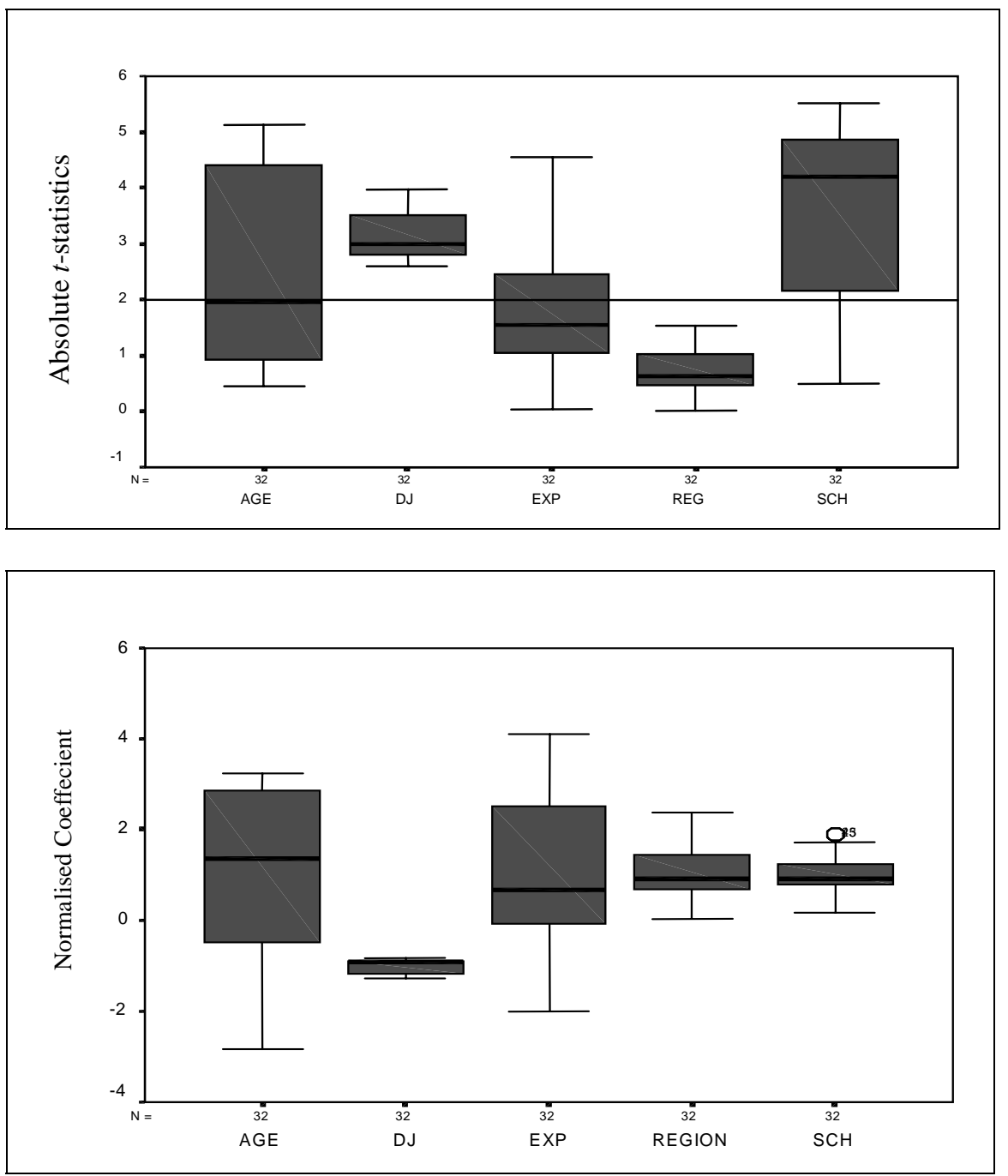

Fig. 5. 
It can be concluded from this fragile analysis that schooling proves to be robust and statistically significant variable in all alternative specifications, as expected higher earnings in the urban informal sector is associated with the schooling. Almost half of the coefficients of experience also show significant results. Contrary to the expectations, age variable shows the fragile results. Regional dummy variable is insignificant in all the alternative specifications. The other important result is that the dummy variable of on the job-training shows much more robust and significant results, it shows the positive association between earnings and training in the urban informal services sector of Pakistan. ${ }^{7}$

\section{CONCLUSION}

The paper presents the results of the wage differentials with respect to human capital accumulation in the Urban Informal Services sector of Pakistan. In the regression results it is shown that schooling is more paying to the self-employed in comparison of the wage earners. These results support the results of the studies Burki and Abbas (1991); Guisinger and Irfan (1980) and Khan (1983). However, as a whole the schooling comes second to experience in wage determination in the Urban Informal Sector of Pakistan.

In recent past some authors Maddala (1993); Siddiqi (1995); Burki and Afaqi (1996) and Dougherty and Jimmenez (1991) concluded that estimation of the Mincer's earnings functions, overestimates the returns to human capital variables (Schooling and Experience) and it will shift the earnings profile associated with progressively greater amounts of education. They have included the interaction term proposed by Richard Sabot in Mincerian model and found it significant. Contrary to their results, we found that interaction term is insignificant across all the specifications. However, only in the regression of a sub sample of the Services (repair and maintenance) group which consists of semi skilled workers, it proves to be highly significant and positive. It follows that for the urban informal services sector the traditional Mincerian specification would have been approximately appropriate. The general conclusion can be drawn that in the unskilled services group such as petty trading and domestic service, education and skill are mismatched. It also might be the case that in these services people have been doing the same jobs for generations or natural ability could be another reason. So the education does not have its impact on experience. However, in skilled services such as repair and maintenance, Mincerian the standard model is inappropriate and the results without interactive term might be misleading. Our results support the Mincer's (1974) specification of the earnings function. However other human capital variable, Schooling and Experience, have the consistent results with above-mentioned authors.

Robustness test proves that most of our variables are stable and robust across the alternative specification. General test of independence strengthens our results by

${ }^{7}$ As the $\mathrm{N}$ takes value $1 \mathrm{in} \mathrm{Dj}$ and Yes takes value 0 . 
rejecting the hypothesis that there is no association between education and earnings in Urban Informal sector of Pakistan. A visual representation and Glejser's test could not find any clue about hetroskedasticity in the model specification.

Normality test has provided confirmation of the superiority of the semilogarithmic earnings functions over its linear counterparts. Results indicate the normal distribution of the residuals.

\section{Policy Implications}

In our results it has been indicated that there is a positive relation between education and earnings in the urban informal sector of Pakistan. However, earnings are not uniquely determined on the basis of the educational attainment of workers, rather placement of the worker in a particular job plays higher a role in wage determination. So, solely investment in education would be fallacy of composition. I do suggest that along with the investment in human capital, sufficient investment in physical capital should not be ignored. Firstly, it could be the reason that education is wholly or partly a signalling mechanism rather than increasing productivity. Secondly, by only increasing investment in human capital would tend to shift the supply of skilled labour in a way that would result in diminishing returns instead of increasing than and would produce "qualification inflation" in the sector. Consequently it can be said that though these results indicate a positive relationship between education and productivity, however for a large group of workers there must be opportunities for productive employment if it is desired for there to be higher productive. So, productivity in the urban informal sector can not be improved, until and unless there is investment in physical capital along with the human capital and sufficient demand that would ensure the employment opportunities in the sector.

It can be suggested that to cope with income inequalities, government can no longer continue a policy of being neglectful or indifferent towards the growth of the informal sector in Pakistan. It is noted that promotion of the informal sector can lead towards the possibility of helping the poor without any major threat to the rich and redistribution of the income.

It has been shown in the results that middle level education has the highest rewards to the workers of the urban informal sector. It might be suggested that more investment should be given to the middle level of education, however, it must not be at the cost of primary education. It is also suggested that to benefit more informal sector workers, schools should be established in the localities where the increased participation of these workers should be guaranteed.

On the job training is another area to improve the earnings in the informal sector of Pakistan. More vocational training schools should be established. For this purpose, existing schools could be used on a shift basis. Those people who are employed during the day can also benefited from such programmes. 
Informal sector should be protected from the whims of the police and other local authorities who are interested more in filling their own coffers rather than improving the working conditions in the informal sector. However, the taxes must be paid by these enterprises.

\section{REFERENCES}

Aftab, Khalid, and Eric Rahim (1989) Barriers to Growth of Informal Sector Firms: A Case Study. Journal of Development Studies 25:4 490-507.

Becker, Gary S. (1964) Human Capital. New York: Columbia University Press.

Blaug, M. (1969) Economics of Education 2. London: Richard Clay Ltd.

Burki, Abid A., and Qaisar Abbas (1991) Earnings Functions in Pakistan's Informal Sector: A Case Study. The Pakistan Development Review 30:4 695-703.

Burki, Abid A., and Ubaidullah (1992) Earnings, Training and Employment in Gujranwala's Urban Informal Sector: Evolution or Involution? Pakistan Economic and Social Review 30:1 49-67.

Burki, Abid A., and Uzma Afaqi (1996) Pakistan's Informal Sector: A Review of Evidence and Policy Issues. Pakistan Journal of Applied Economics 12:1 1-30.

Dougherty C. R. S., and E. Jimenez (1991) The Specification of Earnings Function: Tests and Implications. Economics of Education Review 10:2 85-98.

Guisenger, S., and M. Irfan (1980) Pakistan's Informal Sector. Journal of Development Studies 16:4 412-26.

Guisinger, S. E., H. James E. and Scully Gerald W. Earnings Rate of Return to Education and the Earning Distribution in Pakistan. Economics of Education Review 4: 257-267.

Kemal, A. R. (1995) Retrenchment Policies and Labour Shedding in Pakistan. International Labour Organisation, Geneva. (Occasional Paper No. 17.)

Khan, Shaheen (1983) An Economic Analysis of Personal Earnings in Urban Formal and Informal Sector of Employment. Pakistan Economic and Social Review 21:1\&2 1-23.

Mincer, Jacob (1974) Schooling, Experience, and Earnings. New York and London: National Bureau of Economic Research, Columbia University Press.

Mukherjee, C., H. White, and M. Wuyts (1998) Econometric and Data Analysis for Developing Countries. London: Routledge.

Pakistan, Government of (1996) Economic Survey 1996. Islamabad: Ministry of Finance, Economic Advisor Wing.

Siddiqui, R. (1995) Earnings Function for Pakistan. ISS, The Hague, The Netherlands. (Research Paper.)

Thomas, J. J. (1983) An Introduction to Statistical analysis for Economists. London: Weidenfeld and Nicolson. 


\begin{abstract}
Urban Informal Sector plays an important role to absorb surplus labour and income generation in developing countries. In Pakistan the importance of the sector has been widely recognised, however, most of the studies stress only to the manufacturing activities in the sector. In contrast this study much focuses to the services sector in the informal sector. The present paper explores whether the earnings function specification in this sector conforms to the basic assumptions of the classical regression: whether the condition of homosedasticity and normality hold and therefor whether the conventional tests can be performed. Mincerian earnings function have been estimated in this paper and primary data collected from twin cities (Rawalpindi/Islamabad) of Pakistan has been utilised. For the purpose, firstly sample has been divided into self-employed and wage earners and then into five small scale economic activities namely petty trading, domestic servant, transport, repair and maintenance services and other personnel services. To make the sense of regression coefficients, robustness and normality tests have been applied which lacked in previous studies. Mincer (1974) standard model specification has been checked by including the interaction term proposed by Richard Sabot and found Mincer's standard model appropriate for the urban informal services sector of Pakistan. Investment in physical capital along with human capital is proposed because solely investment in human capital would produce qualification inflation in the sector.
\end{abstract}

